\title{
Hedgers, Speculators and Forward Markets: Evidence From Currency Markets
}

\author{
$\underline{\text { K.F. Radalj }}$ \\ Department of Economics, University of Western Australia, (kradalj@ecel.uwa.edu.au)
}

\begin{abstract}
Since Keynes (1930) and Hicks (1939) propounded their theory of normal backwardation, the issue of whether hedgers must pay speculators an insurance premium has remained controversial. Recent theoretical developments incorporating the existence of market imperfections have validated the existence of an insurance premium charged to hedgers by speculators. Owing to differences in data sets and econometric methods, a consensus has not yet been reached. Drawing inspiration from asset pricing theory a model of currency returns is used, similar to that in Mark (1988) and the importance of speculative influences is tested. The purpose of the paper is to highlight the theoretical and statistical deficiencies of the extant literature and to examine the robustness of previous empirical results to changes in specification. Applications to risk management and forecasting are immediate, as knowledge of any insurance premium is crucial in formulating an optimal hedging strategy and an optimal forecasting model.
\end{abstract}

Keywords: Speculators, normal backwardation.

\section{INTRODUCTION}

The issue of whether futures prices exhibit a bias that compensates speculators for risk dates back to Keynes (1930 and Hicks (1939). They purported that because speculators provide hedgers with the ability to manage risk, they charge a premium for their services. In contrast, modern portfolio theory asserts that in perfect, frictionless markets, only risks that investors cannot diversify will entitle them to earn a premium for bearing risk. However, recent theoretical work that incorporates imperfections such as trading costs and non-marketable positions, allows risk arising from hedging pressure to co-exist with traditional sources of systematic risk, such as market risk - see Hirshleifer (1990) for example.

The question is important for numerous reasons. If premia exist within prices, agents looking to forward prices to form expectations must incorporate premiums into their analysis. In formulating hedging strategies, optimal hedging strategies may depend upon the size of any extant premium. Moreover, an overwhelming body of literature has documented the seemingly biased nature of the forward rate as a predictor of future spot returns. The presence of time-varying risk premia in exchange rate markets has been suggested as a possible source of this bias. ${ }^{1}$ Therefore, it is not surprising that a great deal of

\footnotetext{
${ }^{1}$ For a review of this literature see Engel, C., (1996).
}

research on the existence of futures premia has been conducted. Despite this though, no consensus appears in sight. The work of Carter et al. (1983), Chang (1985) and Bessembinder (1992) seems to support the notion that speculators can charge hedgers a premium for bearing the risks that they are trying to offset. Kolb (1992) and Chatrath et al. (1997) provide conflicting evidence. One reason we may never be certain about whether a speculative premium exists because it is consistent with other reasons, such as superior forecasting ability on the part of agents. These studies analyse simply futures returns, thus whether speculators influence spot and forward market returns remains to be seen.

A recent paper by de Roon et al. (2000) proposes a novel idea whereby not only the particular commodity's speculators charge a premium, but those in like asset classes also contribute to the extent of hedging pressure. They find also that hedging pressure variables affect the underlying asset. However, the results are not completely satisfactory. They measure market returns by the S\&P 500. While the market index will never be completely observable, it seems that a more reliable and relevant measure could be obtained by inserting world equity returns, as measured by the Morgan Stanley Capital Index (MSCI). We address this concern in this paper. Moreover,

\section{EMPIRICAL SPECIFICATION}

Under risk-neutrality, the standard no-arbitrage assumption dictates that forward rates should be 
an unbiased predictor of future spot exchange rates such that:

$$
S_{t+1}=F_{t}^{t+1}+\varepsilon_{t+1}
$$

where $\varepsilon$ is a zero-mean, serially uncorrelated process.

If a risk premium exists, this relationship must be extended to include the premium, $\rho$ :

$S_{t+1}=F_{t}^{t+1}+\rho_{t}+\varepsilon_{t+1}$

Following Mark (1988), we analyse what are notionally called forward returns, that is the $\log$ difference between realized spot rates and forward rates $S_{t}-F_{t}^{t+1}{ }^{2}$ The original hypothesis proposed by Keynes was couched in terms of forward rates and realized spot rates, so this appears to be a more relevant test of the theory than merely analysing futures returns as in Bessembinder (1992) and de Roon et al. (2000). The model above does not stipulate what sources the premium are derived from. Following the theoretical research of Hirshleifer (1990), and empirical papers such as Mark (1988), we include world equity returns and net currency speculators, scaled by the amount of open interest. Therefore, the model is:

$$
\left(S_{t}-F_{t-1}^{t}\right)=\alpha+\beta X S R_{t}+\sum_{i=1}^{5} \gamma_{i} \operatorname{SPECOI}_{i, t-1}+\varepsilon_{t}
$$

where $\mathrm{XSR}_{\mathrm{t}}=\left[\left(\mathrm{MSCI}_{\mathrm{t}}-\mathrm{MSCI}_{\mathrm{t}-1}\right) / \mathrm{MSCI}_{\mathrm{t}-1}\right]-\mathrm{r}^{\mathrm{US}}$, SPECOI $=($ longspec-shortspec $)$ /open interest and $\varepsilon$ is a zero mean, serially uncorrelated process.

\section{DATA}

In measuring forward rates we constructed the theoretical forward rate under covered interest parity. The data was obtained from Datastream and sampled on a monthly basis to avoid the complications of overlapping observations. World excess returns are measured as the monthly returns on the MSCI index in excess of the U.S. dollar interest rate. Speculation is measured as the difference between long and short speculators as reported in the Commodity Futures Trading Commission's (CFTC) Commitment of Traders reports. The CFTC requires that large traders disclose their purpose for trading futures and is

\footnotetext{
${ }^{2}$ The term, 'return' is not strictly true as no capital is invested in entering a forward contract.
}

the most common way of gauging speculative interest applied in the literature. The net amount is scaled by total open interest to account for possible patterns in the amount of futures being traded. The sample spans September 1992 to October 2002 for 130 observations.

Tables 1 and 2 present summary statistics of the variables used in the regression analysis along with augmented Dickey-Fuller tests to establish whether the data displays non-stationary behaviour. Consistent with prior studies, the ADF rejects the null hypothesis of a unit root in returns at the one percent significance level. Furthermore, the measure of speculation is also seen to be stationary. This suggests OLS methods are acceptable procedures to estimate the model.

Over the period speculators tended to be negative across all currencies, perhaps reflecting the fact that the USD appreciated considerably over the period as it has become the store of value for central banks and the unit of account in which global commerce is conducted. Speculators appear to be most volatile in the Australian dollar when compared to the mean amount of contracts, perhaps reflecting that the Australian dollar is often viewed as being a vehicle for speculation.

Table 2 presents summary statistics on world equity returns and the returns to holding forward positions. The null hypothesis of a unit root was rejected at the one percent level in all forward returns and world equity returns. On average the difference between realised spot rates and forward rates was slightly positive, indicating that the forward rate under-predicted realised spot rates on average. World excess returns were slightly negative over the period, in large part due to the recent poor performance of equity markets.

\section{RESULTS}

Generally speaking, none of the models exhibited serially correlated residuals, which is consistent with weak-form efficiency as past price movements cannot be used to predict future returns. Moreover, the constant terms were not significantly different from zero, suggesting that excess returns or another source of risk premium did not exist. ${ }^{3}$ Apart from the Canadian dollar, the residuals did not display significant $\mathrm{ARCH}$

\footnotetext{
${ }^{3}$ It may be possible that a time-varying premium exists that fluctuates around zero giving an insignificant constant term. However, recursive estimation did not show parameter stability to be an issue.
} 
effects, a result consistent with Baillie and Bollerslev (1989) who find that as the sampling interval is lengthened the presence of ARCH effects weakens. In the Canadian dollar case the model was re-estimated using maximum likelihood techniques, Bollerslev-Wooldridge standard errors and employed the $\mathrm{BHHH}$ algorithm. Changing estimation methods impacted the results minimally, and when estimated, the ARCH effects were not significant.

The Australian dollar is often characterised as a commodity currency. Through the Australian economy's reliance upon mineral exports, its value is traditionally tied closely to commodity prices, which in turn are linked to world economic growth. This relationship may reflect the strong relationship between world equity returns and the Australian dollar and is reflected in the negative relationship between Australian dollar movements and world equity returns because the currency is quoted in domestic units per unit of foreign exchange. The Australian dollar is also thought to attract a large degree of speculation. However, from the results in Table 3 it seems that speculators are not capable of earning a premium on Australian dollar forwards. A similar story is told in Table 4, which indicates that world excess returns also explained a significant portion of Canadian dollar forward returns.

\section{TABLE 1: SUMMARY STATISTICS OF SPECULATIVE INTEREST}

Sample based on 131 observations over the period September 1992 to October 2002.

\begin{tabular}{|l|c|c|c|c|c|}
\hline & ASPECOI & CSPECOI & GSPECOI & JSPECOI & SSPECOI \\
\hline Mean & -0.003444 & -0.034743 & -0.015957 & -0.139414 & -0.089271 \\
Std. Dev. & 0.243883 & 0.217877 & 0.248340 & 0.230769 & 0.277910 \\
CofV & -70.8139 & -6.2711 & -15.5631 & -1.65528 & -3.11311 \\
Skewness & 0.190931 & 0.237994 & 0.219948 & 0.515206 & 0.316384 \\
Kurtosis & 2.293147 & 2.327821 & 2.114816 & 2.278102 & 1.857544 \\
Jarque-Bera & 3.523142 & 3.702874 & 5.333117 & 8.639908 & 9.309730 \\
Probability & 0.171775 & 0.157011 & 0.069491 & 0.013300 & 0.009515 \\
& & & & & \\
ADF & $-5.156489 * *$ & $-5.110230 * *$ & $-7.597568 * *$ & $-4.948697 * *$ & $-6.144241 * *$ \\
\hline
\end{tabular}

$* *$ denotes significant at the one percent level.

TABLE 2: FORWARD MARKET AND WORLD EQUITY RETURNS

Sample based on 130 observations over the period September 1992 to October 2002.

\begin{tabular}{|l|c|c|c|c|c|c|}
\hline & AFWDRET & CFWDRET & GFWDRET & JFWDRET & SFWDRET & XSRET \\
\hline Mean & 0.001501 & 0.001858 & 0.000207 & 0.003312 & 0.003004 & -0.000753 \\
Std. Dev. & 0.026684 & 0.014002 & 0.021166 & 0.033322 & 0.030613 & 0.039884 \\
CofV & 17.77748 & 7.53606 & 102.2512 & 10.06099 & 10.19075 & -52.9668 \\
Skewness & 0.096163 & -0.190466 & -0.477935 & -0.675421 & -0.053223 & -0.849552 \\
Kurtosis & 2.519939 & 2.505799 & 4.852573 & 3.679882 & 3.056588 & 5.156055 \\
JB & 1.448672 & 2.108950 & $23.53930 * *$ & $12.3880 * *$ & 0.078720 & $40.81744 * *$ \\
ADF & $-8.6255^{* *}$ & $-8.8449 * *$ & $-10.3106 * *$ & $-6.5368 * *$ & $-8.1086^{* *}$ & $-4.0103 * *$ \\
\hline
\end{tabular}

** denotes significant at the one percent level. 
TABLE 3 - AUSTRALIAN DOLLAR

\begin{tabular}{|c|r|r|r|r|}
\hline Variable & \multicolumn{1}{|c|}{ Coefficient } & \multicolumn{1}{c|}{ Std. Error } & \multicolumn{1}{c|}{ t-Statistic } & \multicolumn{1}{c|}{ Prob. } \\
\hline C & & & & \\
XSRET & -0.000687 & 0.002615 & 0.262671 & 0.7932 \\
ASPECOI(-1) & -0.006611 & 0.055853 & $-4.924914 * *$ & 0.0000 \\
CSPECOI(-1) & -0.008134 & 0.010788 & -0.695767 & 0.4879 \\
GSPECOI(-1) & 0.016215 & 0.010051 & 1.613264 & 0.1092 \\
JSPECOI(-1) & 0.006199 & 0.010263 & 0.604036 & 0.5469 \\
SSPECOI(-1) & -0.015802 & 0.009417 & -1.678039 & 0.0959 \\
& & & & \\
Adj R-squared & 0.137798 & D-W & 1.887154 & \\
ARCH & 2.481815 & & & \\
& & & & \\
\hline
\end{tabular}

** denotes significant at the one percent level.

As the world's second largest economy, it is little surprise that movements in the Yen are correlated with world equity returns. However, Table 6 indicates that there was no sign that speculation influenced Japanese forward returns. Interestingly, Table 7 shows that the Swiss franc does not exhibit a strong correlation with world equity returns. The franc is probably viewed as a store of value and as such would not be expected to exhibit a strong correlation with global equity returns. Australian dollar speculators were marginally significant in explaining Swiss franc forward returns over the period. Why this arises is not immediately evident given that the Swiss and Australian economies have very little association.

TABLE 4 - CANADIAN DOLLAR

\begin{tabular}{|c|r|l|r|r|}
\hline Variable & \multicolumn{1}{|c|}{ Coefficient } & \multicolumn{1}{c|}{ Std. Error } & \multicolumn{1}{|c|}{ t-Statistic } & \multicolumn{1}{c|}{ Prob. } \\
C & & & & \\
XSRET & -0.001114 & 0.001450 & 0.768283 & 0.4438 \\
ASPECOI(-1) & 0.001206 & 0.005315 & 0.226724 & 0.8210 \\
CSPECOI(-1) & -0.001115 & 0.005824 & -0.191448 & 0.8485 \\
GSPECOI(-1) & 0.003788 & 0.004941 & 0.766618 & 0.4448 \\
JSPECOI(-1) & -0.001446 & 0.005475 & -0.264027 & 0.7922 \\
SSPECOI(-1) & -0.005297 & 0.005289 & -1.001574 & 0.3185 \\
& & & & \\
Adj R-squared & 0.093363 & D-W & 2.130010 & \\
& & ARCH & $9.851376^{* *}$ & \\
& & & & \\
\hline
\end{tabular}

** denotes significant at the one percent level.

TABLE 5 - BRITISH POUND

\begin{tabular}{|c|r|r|r|r|}
\hline Variable & \multicolumn{1}{|c|}{ Coefficient } & \multicolumn{1}{c|}{ Std. Error } & \multicolumn{1}{c|}{ t-Statistic } & Prob. \\
\hline C & & & & \\
XSRET & 0.000943 & 0.002199 & 0.428685 & 0.6689 \\
ASPECOI(-1) & -0.045864 & 0.046971 & -0.976443 & 0.3308 \\
CSPECOI(-1) & 0.013152 & 0.007990 & 1.645995 & 0.1023 \\
GSPECOI(-1) & -0.012965 & 0.009072 & 1.429145 & 0.1555 \\
JSPECOI(-1) & 0.002290 & 0.008631 & 0.265344 & 0.7912 \\
SSPECOI(-1) & 0.001704 & 0.007919 & 0.215113 & 0.8300 \\
& & & & \\
\hline
\end{tabular}




\begin{tabular}{|l|l|l|l|l|}
\hline Adj R-squared & 0.030896 & D-W & 1.869597 & \\
ARCH & 0.777853 & & & \\
\hline$* *$ denotes significant at the one percent level & & \\
\hline
\end{tabular}

** denotes significant at the one percent level

TABLE 6 - JAPANESE YEN

\begin{tabular}{|c|r|r|r|r|}
\hline Variable & Coefficient & Std. Error & \multicolumn{1}{c|}{ t-Statistic } & Prob. \\
\hline C & -0.000227 & 0.003465 & -0.065558 & 0.9478 \\
XSRET & -0.142936 & 0.074529 & $-1.917852 *$ & 0.0574 \\
ASPECOI(-1) & -88.93143 & 111.0138 & -0.801084 & 0.4246 \\
CSPECOI(-1) & -225.2470 & 721.4778 & -0.312202 & 0.7554 \\
GSPECOI(-1) & -156.2011 & 584.8590 & -0.267075 & 0.7899 \\
JSPECOI(-1) & -1751.052 & 1090.667 & -1.605488 & 0.1110 \\
SSPECOI(-1) & -81.19516 & 599.6255 & -0.135410 & 0.8925 \\
Adj R-squared & 0.020461 & D-W & 2.049841 & \\
ARCH & 2.857191 & & & \\
\end{tabular}

*denotes significant at the ten percent level.

TABLE 7 - SWISS FRANC

\begin{tabular}{|c|r|r|r|r|}
\hline Variable & Coefficient & \multicolumn{1}{|c|}{ Std. Error } & \multicolumn{1}{c|}{ t-Statistic } & \multicolumn{1}{c|}{ Prob. } \\
\hline C & & & & \\
XSRET & 0.004363 & 0.003221 & 1.354783 & 0.1780 \\
ASPECOI(-1) & -0.068545 & 0.068778 & 0.996620 & 0.3209 \\
CSPECOI(-1) & 0.010390 & 0.011700 & $-1.784588^{*}$ & 0.0768 \\
GSPECOI(-1) & 0.011709 & 0.013284 & 0.782128 & 0.4356 \\
JSPECOI(-1) & 0.006153 & 0.012638 & 0.946087 & 0.3460 \\
SSPECOI(-1) & -0.000215 & 0.011596 & -0.018520 & 0.6272 \\
& & & & 0.9853 \\
Adj. R-squared & 0.006697 & D-W & 1.844755 & \\
ARCH & 0.061450 & & & \\
\end{tabular}

*denotes significant at the ten percent level.

Comparing across currencies, our results differ somewhat from de Roon et al. (2000). They found the Deutschemark to significantly influence European currencies. Unfortunately due to the introduction of the Euro, including the DM in our sample would have greatly reduced the number of observations. Also they found that each currency's speculators significantly affect futures returns, in contrast to the above results which indicate that this is seldom the case. It may be that futures markets have become more efficient in incorporating this information as our sample is more recent, or that speculative premiums have attracted more speculators such that the speculative premium has been bid towards zero. Also it shows that using world equity returns to condition for systematic risk may be an important consideration.

Furthermore, it seems that global economic growth prospects are important factors for economies that depend upon world economic performance, such as Australia. This is a very interesting result, as it indicates that for foreign investors, investment in such currencies entails added risk, due to the presence of correlation between the currency and the world equity market in general. This is in contrast to studies into Arbitrate Pricing Theory, which often fail to find significant currency effects. Thus, if fund managers wish to pick stocks based upon individual merit, it may pay them to hedge their 
foreign currency exposure to eliminate this component of risk within such assets.

\section{CONCLUSIONS}

The issue of whether speculators earn a premium for absorbing risk from hedgers has been extensively debated, with conflicting empirical evidence. Following de Roon et al. (2002), we include currency speculators across different currencies in our empirical model. The test is also a more direct test of the normal backwardation theory as we analyse how forward rates relate to realised spot rates, as opposed to analysing futures returns, which is commonly applied in the literature.

We find no evidence that speculators are capable of charging hedgers a premium for bearing risk. However, we do find significant evidence of systematic risk factors in currency markets from the perspective of a U.S. investor, using the MSCI as the benchmark market index.

\section{ACKNOWLEDGEMENTS}

The author would like to acknowledge the financial assistance of the Hackett Postgraduate Scholarship. I would like to thank Michael McAleer for helpful comments and suggestions.

\section{BIBLIOGRAPHY}

Baillie, R.T., Bollerslev, T., 'The Message in Daily Exchange Rates: A Conditional Variance Tale', Journal of Business and Economic Statistics, 7, pp. 297-305.

Bessembinder, H., (1992), 'Systematic Risk, Hedging Pressure and Risk Premiums in Futures Markets', Review of Financial Studies, 5, pp. 637667.
Carter, C.A., Rausser, G.C., Schmitz, A., (1983), 'Efficient Asset Portfolios and the Theory of Normal Backwardation', Journal of Political Economy, 91, pp. 319-331.

Chang, E.C., (1985), 'Returns to Speculators and the Theory of Normal Backwardation', Journal of Finance, 40, pp. 193-208.

Charath, A., Lian, Y., Song, F., (1997), 'Commitment of Traders, Basis Behaviour and the Issue of Risk Premia in Futures Markets', Journal of Futures Markets, 17, pp.707-731.

de Roon, F.A., Nijman, T.E., Veld, C., (2000), 'Hedging Pressure Effects in Futures Markets', Journal of Finance, 55, pp. 1437-1456.

Engel, C.E., (1996), 'The Forward Discount Anomaly and the Risk Premium: A Survey of Recent Evidence', Journal of Empirical Finance, 3, pp. 123-192.

Hicks, J.R, (1939), Value and Capital, Cambridge: Oxfor University Press.

Hirshleifer, D., (1990), 'Hedging Pressure and Futures Price Movements in a General Equilibrium Model', Econometrica, 58, pp. 411428.

Keynes, J.M., (1930), A Treatise on Money, Vol. II, Macmillan, London.

Kolb, R.W., (1992), 'Is Normal Backwardation Normal?', Journal of Futures Markets, 12, pp. 75 91.

Mark, N.C., (1988), 'Time-Varying Beta and Risk Premia in the Pricing of Forward Foreign Exchange Contracts', Journal of Financial Economics, 22, pp. 335-354. 